História, Aplicações, Atividade e Modificações da Citrinina

\author{
Cruz, J. S.; Costa, G. L.; Figueroa-Villar, J. D.*
}

Rev. Virtual Quim., 2016, 8 (3), 650-664. Data de publicação na Web: 17 de maio de 2016

http://rvq.sbq.org.br

\title{
History, Applications, Activity and Changes of Citrinin
}

Abstract: Citrinin is a natural product obtained from fungi and with good biological activity. Because this compound also presents toxicity, especially being nephrotoxicity, its structural modification is important to obtain new potential pharmacological agents without toxicity. This article presents the history, obtention methods, synthesis, structural modification, evaluation and biological activity of citrinin.

Keywords: Citrinin; Penicillium; mycotoxins; biosynthesis; antibiotic; nephrotoxicity.

\section{Resumo}

A Citrinina é um produto natural obtido de fungos e com boa atividade biológica. Como ela também apresenta certa toxidez, especialmente sendo nefrotóxica, é importante sua modificação estrutural para obter novos fármacos sem essa toxidez. Este artigo apresenta a história, os métodos de obtenção, síntese, modificação estrutural, avaliação e atividade biológica da citrinina.

Palavras-chave: Citrinina; Penicillium; micotoxinas; biossíntese; antibiótico;

nefrotóxica.

\footnotetext{
* Instituto Militar de Engenharia, Seção de Engenharia Química, Grupo de Química Medicinal, Praça General Tibúrcio, 80, Praia Vermelha, Urca, CEP 22290-270, Rio de Janeiro-RJ, Brasil.

M jdfv2009@gmail.com

DOI: $\underline{10.5935 / 1984-6835.20160049}$
} 


\section{História, Aplicações, Atividade e Modificações da Citrinina} Jacqueline S. Cruz, ${ }^{a}$ Gisela Lara da Costa, ${ }^{b}$ Jose Daniel Figueroa-Villar ${ }^{a, *}$

a Instituto Militar de Engenharia, Seção de Engenharia Química, Grupo de Química Medicinal, Praça General Tibúrcio, 80, Praia Vermelha, Urca, CEP 22290-270, Rio de Janeiro-RJ, Brasil

${ }^{\mathrm{b}}$ Fundação Oswaldo Cruz, Instituto Oswaldo Cruz, Laboratório de Taxonomia, Bioquímica e Bioprospecção de Fungos, Av. Brasil n.4365, Pavilhão Leonidas Deane, sala 604, Manguinhos, CEP 21040-900 - Rio de Janeiro-RJ, Brasil.

*jdfv2009@gmail.com

Recebido em 13 de maio de 2015. Aceito para publicação em 10 de maio de 2016

\section{Introdução}

2. Citrinina

3. Produção de Citrinina

4. Biossíntese e Síntese da Citrinina

5. Modificações estruturais

6. Atividade Biológica e Toxidez da Citrinina

7. Considerações Finais

\section{Introdução}

Os fungos têm chamado atenção como fontes importantes de metabólitos secundários, principalmente pela diversidade estrutural e pelo seu potencial biológico para a descoberta de novos medicamentos.

Ao longo das décadas a importância dos fungos nos processos biotecnológicos foi sendo reconhecida por produzirem uma rica fonte de metabólitos ativos com amplas aplicações como: antibióticos, antiparasíticos, agroquímicos, imunossupressores e agentes reguladores de colesterol. ${ }^{1}$

Dentro deste aspecto podemos destacar a penicilina (1-antibiótico), a ciclosporina (2 regulador do sistema imunolológico) e a lovastatina (3 -inibidor da biossíntese de colesterol), que foram isoladas dos fungos Penicillium notatum, Tolypocladium inflatum e Aspergillus terreus, respectivamente (Figura 1). 


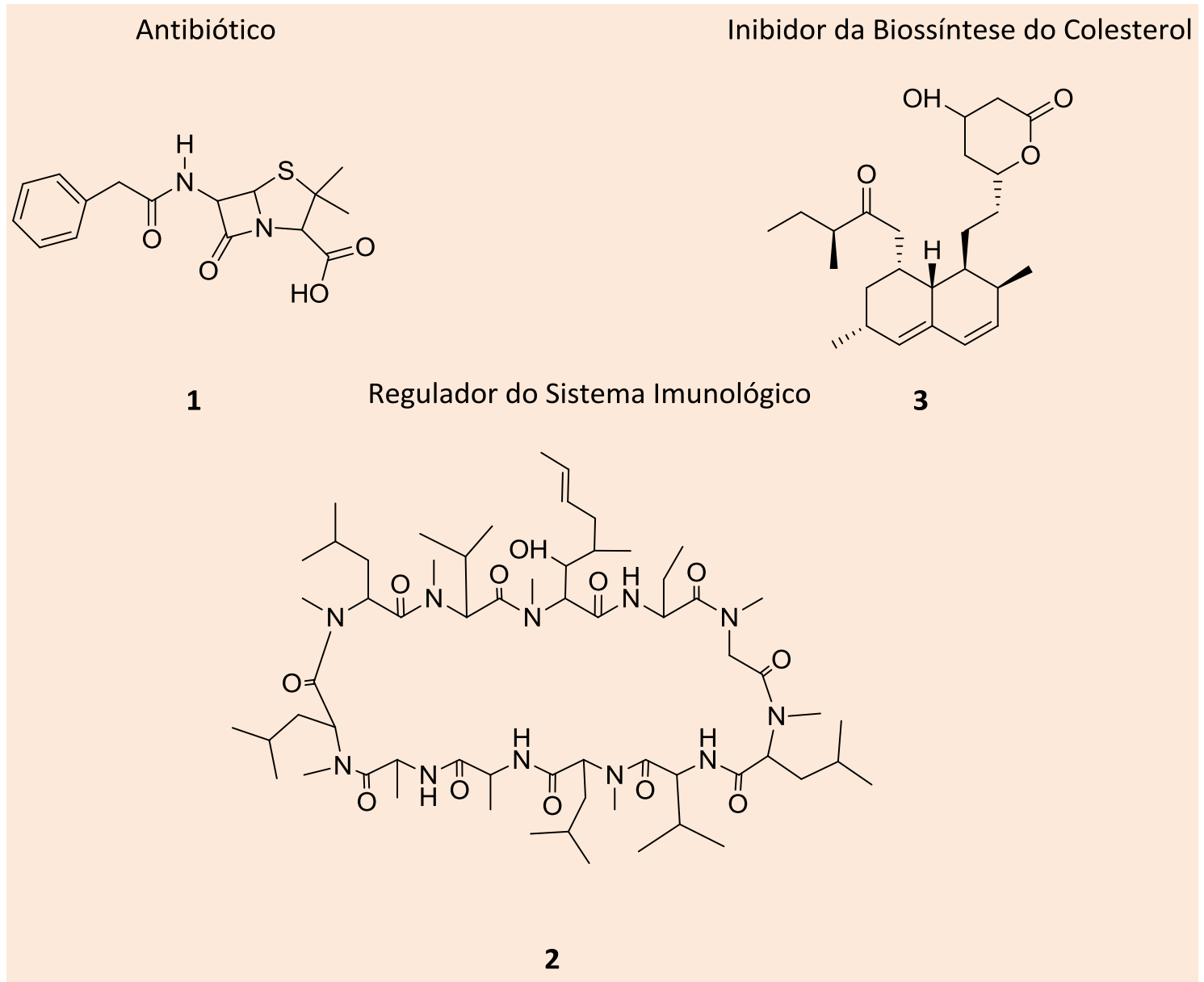

Figura 1. Exemplo de três metabólitos biologicamente ativos isolados de fungos. (1) Penicilina - antibiótico, (2) Ciclosporina - regulador do sistema imunológico e (3) Lovastatina - regulador da biossíntese do colesterol

Apesar do grande interesse das indústrias farmacêuticas nos metabólitos fúngicos bioativos, esses organismos também são capazes de produzir metabólitos potencialmente tóxicos capazes de causar prejuízos na saúde animal e humana. Estes compostos, conhecidos como micotoxinas, são frequentemente encontrados contaminando grãos, frutos, rações e leite. Devido aos seus efeitos tóxicos e a sua alta resistência a tratamentos térmicos, sua presença, além de ser perigosa para a saúde, causa impactos na economia, gerando perdas na criação de animais e na produção de alimentos. ${ }^{2-3}$

Micotoxinas como aflatoxinas (4) e ocratoxinas (5) produzidas por espécies do gênero Aspergillus (Figura 2), são hepatotóxicas, nefrotóxicas e carcinogênicas. Enquanto a citrinina produzida pelo fungo Penicillium citrinum é nefrotóxica para suínos. ${ }^{4}$ 
<smiles>COc1c2c(cc3oc(=O)c4c(c13)CCC4=O)[C@@H]1C=CO[C@@H]1O2</smiles>

4<smiles>C[C@H]1Cc2c(Cl)cc(C(=O)NC(Cc3ccccc3)C(=O)O)c(O)c2C(=O)O1</smiles>

5

Figura 2. Estrutura das micotoxinas - aflatoxina B (4) e ocratoxina B (5)

\section{Citrinina}

A citrinina é um metabólito fúngico isolado pela primeira vez em 1931. Conhecida também como antimicina, foi caracterizada como antibiótica em 1941, mas, devido as suas propriedades tóxicas não pode ser usada para aplicações terapêuticas.5-7

Esta micotoxina é amplamente distribuída, pois tem sido encontrada como contaminante natural em vários tipos de grãos, frutas, cereais e ração animal.8 Ela pode ser produzida por diferentes fungos, principalmente por espécies da família Trichocomaceae. Originalmente foi isolada de culturas de Penicillium citrinum Thom, mas ao longo dos anos, estudos envolvendo a produção e isolamento desta toxina, outras espécies dos gêneros Penicillium, Aspergillus e Monascus também vem sendo observados.9-18
A citrinina é um metabólico benzopirânico (C13H14O5, IUPAC: (3R, 4S)-4,6 -Diidro-8hidroxi-3, 4,5-trimetil-6-oxo-3H-2benzopirano-7-ácido carboxílico), com peso molecular de $250,25 \mathrm{~g} / \mathrm{mol}$, que quando cristalizada em etanol absoluto forma cristais amarelos. Apresenta ponto de fusão na faixa de $175-176{ }^{\circ} \mathrm{C}$, sendo solúvel em solventes orgânicos e insolúvel em água.3,8

A estrutura da citrinina foi proposta por Brown e colaboradores em 1948.19 Estudos de espectroscopia de infravermelho mostraram a presença de ligações de hidrogênio intramoleculares, sugerindo que as duas conformações desta molécula (Figura 3) estariam em equilíbrio.20 A conformação correta da estrutura foi confirmada a partir de análises de ressonância magnética nuclear, realizadas por Mathielson e Whalley que também determinaram as orientações estéricas dos dois grupos metila e dos dois átomos de hidrogênio em carbonos sp3 do anel heterocíclico. ${ }^{21}$

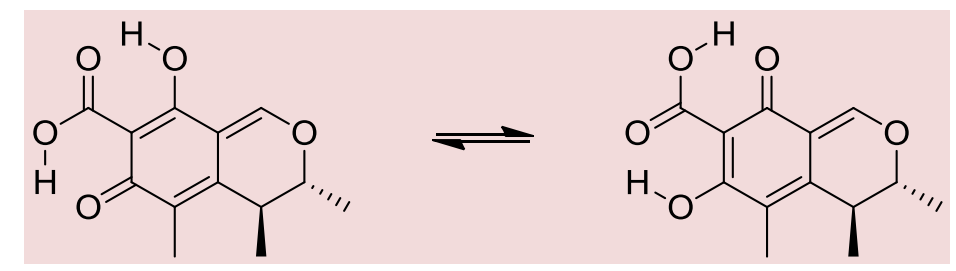

Figura 3. Tautômeros da citrinina 


\section{Produção de Citrinina}

A citrinina pode ser produzida pelos fungos em meios de cultura sintéticos líquidos ou sólidos, grãos e frutas, em condições diversas. Sabe-se que a composição do meio de cultura afeta consideravelmente a produção de micotoxinas por uma cultura pura, daí é necessário buscar um meio de cultura no qual a cepa da espécie fúngica escolhida seja capaz de produzir as toxinas desejadas em grande escala para estudos posteriores de sua atividade no sistema biológico.

O primeiro relato da produção de citrinina em meio de cultura ocorreu em 1931, quando seus descobridores investigavam a substância de cor amarela produzida pelo fungo Penicillium citrinum. A espécie em questão foi crescida em meio de cultura Czapek líquido modificado, a $28^{\circ} \mathrm{C}$. O filtrado da cultura foi acidificado para a precipitação do produto bruto, e purificado por recristalização em etanol. ${ }^{5}$

Para a produção e o isolamento da citrinina, Damodaran e colaboradores usaram dois meios de cultura para cultivar os fungos Penicillium citrinum e Aspergillus candidus: meio Timonin's contendo glicose $(80,0 \mathrm{~g})$, $\mathrm{NaNO}_{3}(3,0 \mathrm{~g}), \mathrm{KH}_{2} \mathrm{PO}_{4}(1,0 \mathrm{~g}), \mathrm{KCl}(0,5 \mathrm{~g})$, $\mathrm{MgSO}_{4} \cdot 7 \mathrm{H}_{2} \mathrm{O}(0,05 \mathrm{~g}), \mathrm{Fe}_{2}\left(\mathrm{SO}_{4}\right)_{3} \cdot 7 \mathrm{H}_{2} \mathrm{O}(0,005$ g), $\mathrm{ZnSO}_{4}(0,005 \mathrm{~g})$ por litro de água destilada e o meio Richard's constituído de glicose $(30,0 \mathrm{~g}), \mathrm{KNO}_{3}(10,0 \mathrm{~g}), \mathrm{KH}_{2} \mathrm{PO}_{4}(5,0 \mathrm{~g})$, $\mathrm{MgSO}_{4} .7 \mathrm{H}_{2} \mathrm{O}(2,6 \mathrm{~g})$ e traços de $\mathrm{FeCl}_{3}$. Os fungos foram crescidos em temperatura ambiente por 20 dias. Neste estudo observaram que, para ambos os fungos, o melhor meio de cultivo para a produção da toxina foi o meio Timonin's. ${ }^{6} \quad$ Após a esporulação da cultura de Penicillium que estava preservada em agar slant, o fungo foi inoculado em quatro litros de meio contendo $4 \%$ sacarose e $2 \%$ de extrato de levedura, sendo incubado no período de 10 a 14 dias, em temperatura ambiente e sem agitação. ${ }^{22}$

O meio YES ( $2 \%$ de extrato de levedura, $15 \%$ sacarose) tem sido muito utilizado para o estudo das micotoxinas, principalmente da citrinina. Pelo fato da composição deste meio de cultura favorecer a produção de toxinas pelos fungos em maior quantidade. ${ }^{10,23-26} \mathrm{~A}$ composição química do substrato influencia a produção de micotoxina, quanto maior a quantidade de carboidratos e lipídeos, mais intensa a micotoxigênese. ${ }^{27}$ Pesquisas envolvendo linhagens de Monascus ruber $e$ Monascus purpureus, verificaram produção de citrinina em concentrações relativamente altas, 370 e $240 \mathrm{mg} \mathrm{L}^{-1}$, respectivamente, em meio YES. Também observaram que concentrações de etanol, $28 \mathrm{~g} \mathrm{~L}^{-1}$; e glicose, $45 \mathrm{~g} \mathrm{~L}^{-1}$, favoreceram a produção de citrinina. No entanto, a presença de etanol em altas concentrações, $45 \mathrm{~g} \mathrm{~L}^{-1}$, inibe o crescimento fúngico e consequentemente a produção deste metabólito. Do mesmo modo, fontes de nitrogênio como ureia e metionina também desfavoreceram a produção de citrinina. ${ }^{13}$

Mais recentemente a citrinina foi produzida significativamente por uma linhagem de Penicillium corylophilum isolada de mosquito, quando inoculada em meio líquido YES. Esta pesquisa também demonstrou que quando esta espécie fúngica foi submetida ao estresse biológico com o fungo Beauveria bassiana a produção da citrinina aumentou em $65 \%{ }^{26}$

\section{Biossíntese e Síntese da Citrinina}

$\mathrm{Na}$ literatura observa-se um grande número de estudos relacionados com a rota biossintética na formação da citrinina. Os primeiros trabalhos sugerem que a citrinina produzida pela espécie Aspergillus candidus é derivada de pentacetídeos formados pela condensação de cinco grupos de acetato e de três átomos de carbono. ${ }^{28-33}$ Mais recentemente a rota biossintética foi confirmada utilizando marcadores isotópicos, sugerindo que a formação da citrinina seja através de tetracetídeos em culturas de Monascus ruber (Figura 4). ${ }^{14}$ 


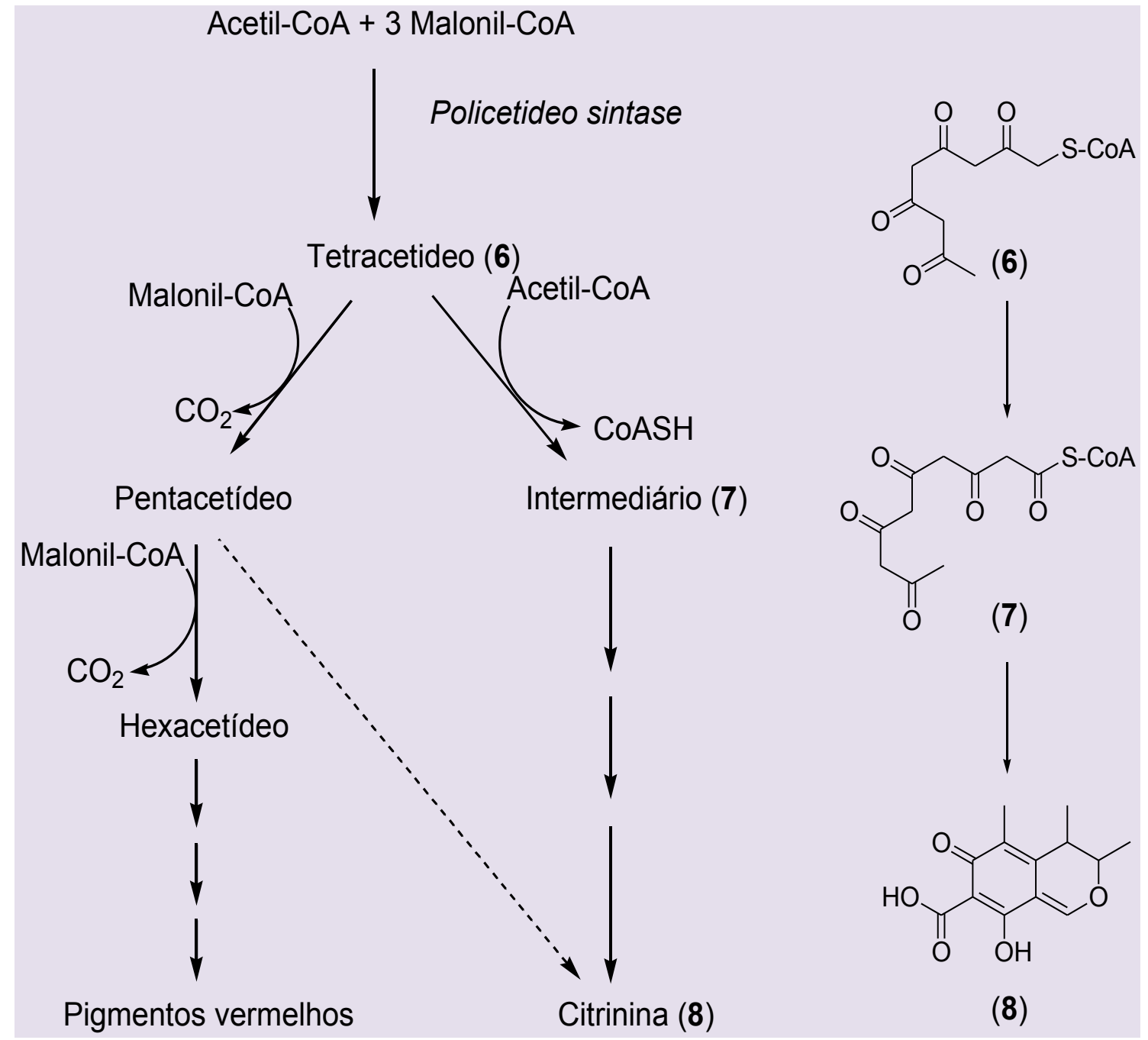

Figura 4. Rota Biossintética da formação da citrinina ${ }^{14}$

A síntese da citrinina foi proposta em 1949 (Figura 5). ${ }^{34}$ Inicialmente o composto fenol A (5-((2R, 3S)-3-(3,5-hidroxibutan-2-il)4-metilbenzeno-1,3-diol )(9)foi carboxilado para a forma ácida (10). O produto desta reação foi submetido à reação de Gattermann, que consiste na conversão do fenol a aldeído aromático pela reação com cianeto/ $\mathrm{HCl}$ na presença de zinco como catalisador, formando um intermediário (11), que fecha o anel após a adição de ácido sulfúrico para formar a citrinina (8).

Em 1986, Barber e Stauton publicaram um artigo sobre a síntese da citrinina empregando a litiação benzílica seletiva como transformação fundamental para a formação de um estereoisômero não natural da toxina. ${ }^{35}$ A síntese (Figura 6) inicia-se com a litiação do etilbenzeno (13) na posição benzílica, seguida por acilação do ânion toluato intermediário em baixa temperatura. Subsequentemente há a redução da benzil cetona(14) para a formação do treo-dimetilbiciclo (15). Posteriormente a redução com DIBAL (16) e subsecutivamente a abertura do anel para a formação do álcool (17). A próxima etapa foi então desmetilar os grupos metoxi para fornecer o 1,3-difenol (18). Em seguida esse intermediário foi carboxilado em condições tampão, para fornecer o ácido (19), também conhecido como "Fenol B". Esse último intermediário foi formilado com ortoformiato de trimetila e ácido, ciclizando para se obter a estrutura da citrinina (8). 
<smiles>Cc1c(O)cc(O)cc1[C@@H](C)[C@@H](C)O</smiles>

( 9 )

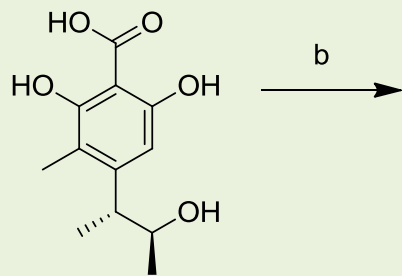

(10)<smiles>Cc1c(C)c(C=O)c(O)c(C(=O)O)c1O</smiles><smiles>C=COC(=O)c1c(C)c(C)c(CO)c(O)c1C(=O)O</smiles>

(11)

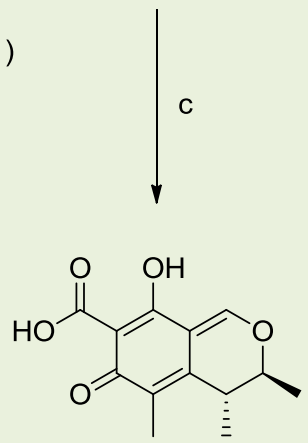

(12)

( 8 )

Figura 5. Esquema da Síntese da Citrinina proposto por Cartwright. ${ }^{34}$ Reagentes e condições reacionais: a) $\mathrm{KHCO}_{3} / \Delta, \mathrm{HCl}$; b) $\mathrm{HCN}, \mathrm{Zn} / \mathrm{HCl}$; c) $\mathrm{H}_{2} \mathrm{SO}_{4}$

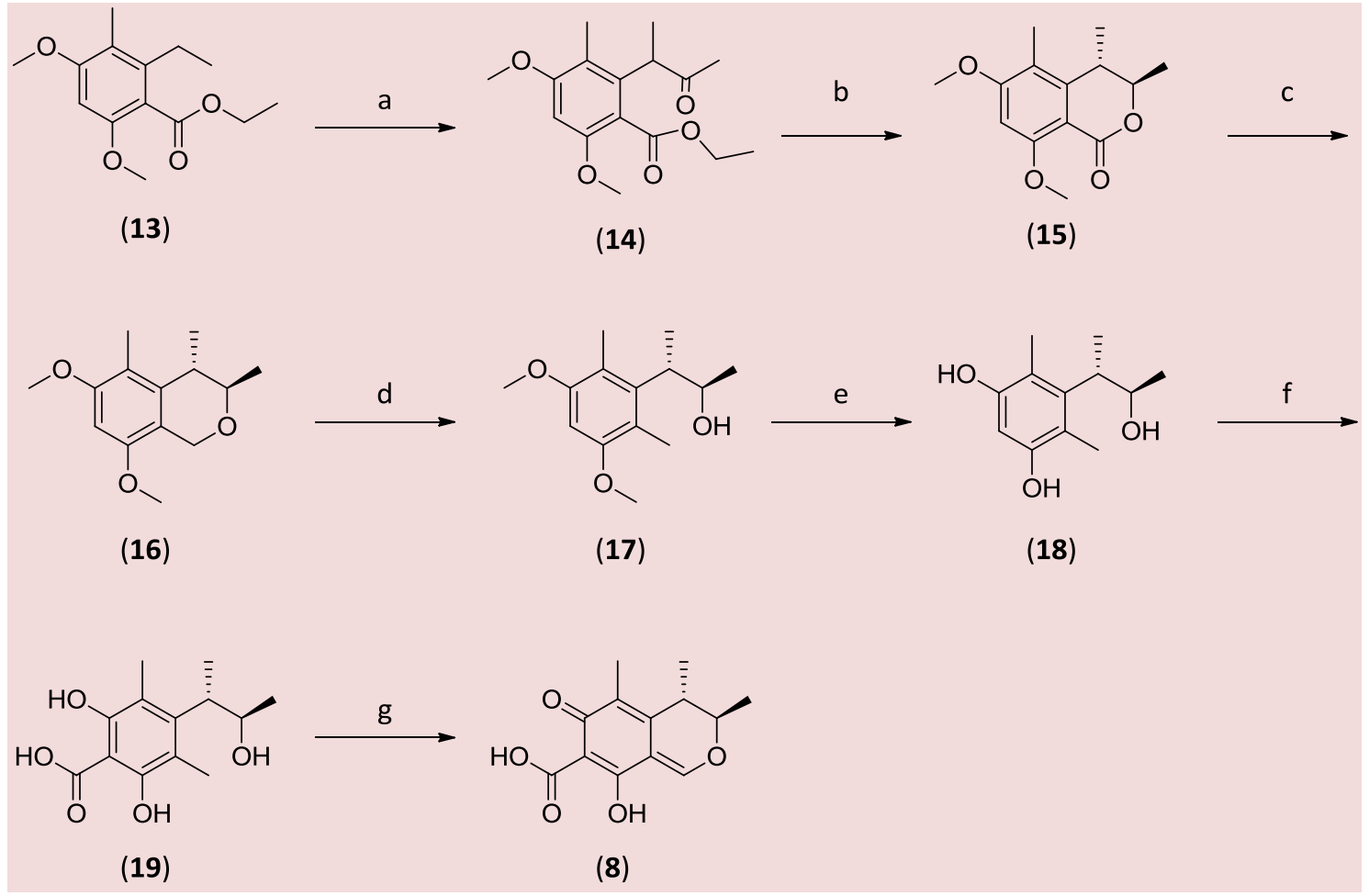

Figura 6. Esquema da Síntese da Citrinina proposto por Barber e Stauton. ${ }^{35}$ Reagentes e condições reacionais: a) $\mathrm{LDA}, \mathrm{THF},-78^{\circ} \mathrm{C}$; $\mathrm{AcCl},-130^{\circ} \mathrm{C}$; b) $\mathrm{NaBH}_{4}, \mathrm{MeOH}$; c) DIBAL, Tolueno; d) $\mathrm{H}_{2}, \mathrm{Pd} / \mathrm{C}, \mathrm{AcOH}, \mathrm{MeOH}$; e) $\mathrm{BBr}_{3}, \mathrm{CH}_{2} \mathrm{Cl}_{2}$; f) $\mathrm{KHCO}_{3}, \mathrm{CO}_{2}$, glicerol, $150{ }^{\circ} \mathrm{C}$; g) $\mathrm{HC}(\mathrm{OEt})_{3}, \mathrm{HCl}$ 
Em um estudo posterior, pesquisadores usaram uma base de amida quiral, a fim de desprotonar seletivamente apenas um dos prótons alquilo pró-quirais (21), com um excesso enantiomérico de $70 \%$ e diastereosseletividade de 3:1 (Figura 7). O produto foi então convertido através de uma treo-lactona para a formação não natural de citrinina (8). ${ }^{36}$<smiles></smiles>

(20)<smiles>CCOC(=O)c1c(CC)cc(OC)cc1OC</smiles>

(21)<smiles>CCOC(=O)c1c(CC)cc(OC)cc1OC</smiles>

(22)<smiles>COc1cc(OC)c2c(c1)[C@H](C)[C@H](C)OC2=O</smiles>

(23)<smiles>COc1cc(OC)c2c(c1)[C@H](C)[C@H](C)OC2=O</smiles>

(24)<smiles>C[C@H]1OC(=O)c2c(O)cc(O)cc2[C@H]1C</smiles>

(25)<smiles>Cc1c(O)cc(O)cc1[C@@H](C)[C@H](C)O</smiles>

(26)

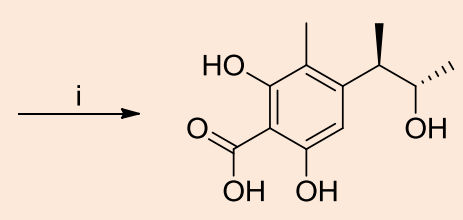

(27)

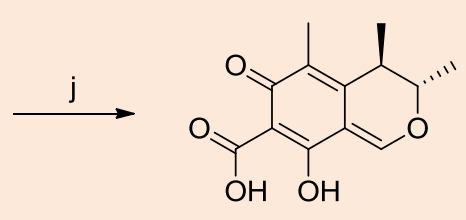

(8)

Figura 7. Esquema da síntese de citrinina proposto por Regan e Staunton. ${ }^{36}$ Reagentes e condições reacionais: a) THF, $-78^{\circ} \mathrm{C}$; b) $\mathrm{MeCHO}$; c) LiOH (aq); d) liofilização; e)PDC, DMF; f) $\mathrm{NaBH}_{4}, \mathrm{MeOH}$; g) $\mathrm{BBr}_{3} / \mathrm{CH}_{2} \mathrm{Cl}_{2}$; h) NaAlH$\left(\mathrm{OCH}_{2} \mathrm{CH}_{2} \mathrm{OCH}_{3}\right)_{2}$, xileno, refluxo; i) $\mathrm{CO}_{2}, \mathrm{KHCO}_{3}$, glicerol, $\left.150^{\circ} \mathrm{C} ; \mathrm{j}\right)\left(\mathrm{Et}_{2} \mathrm{O}\right)_{3} \mathrm{CH}, \mathrm{HCl}$

Rodel e Gerlach relataram a síntese da citrinina (8), em 1995, a partir do dibenzilbrometo de arilo protegido (28). ${ }^{37} \mathrm{~A}$ transformação deste material com o reagente de Grignard em presença do 1,5ciclo-octadieno cobre(I) como catalisador proporcionou a abertura do anel epóxido (trans-2,3-di-metil-oxirano), para formar o álcool (2S,3S)-30 com rendimento de 76\%. A configuração do C-2 da molécula (2S,3S)-30 pode ser invertida através da reação de Mitsunobu com ácido fórmico como nucleófilo, seguido por hidrólise do intermediário (31) formando o álcool (2R,3S)32. A fim de completar a síntese de ocorrência natural da citrinina, foi feita a remoção dos grupos benzila e, em seguida, a sequência de carboxilação, formilação e ciclização do anel (Figura 8). 


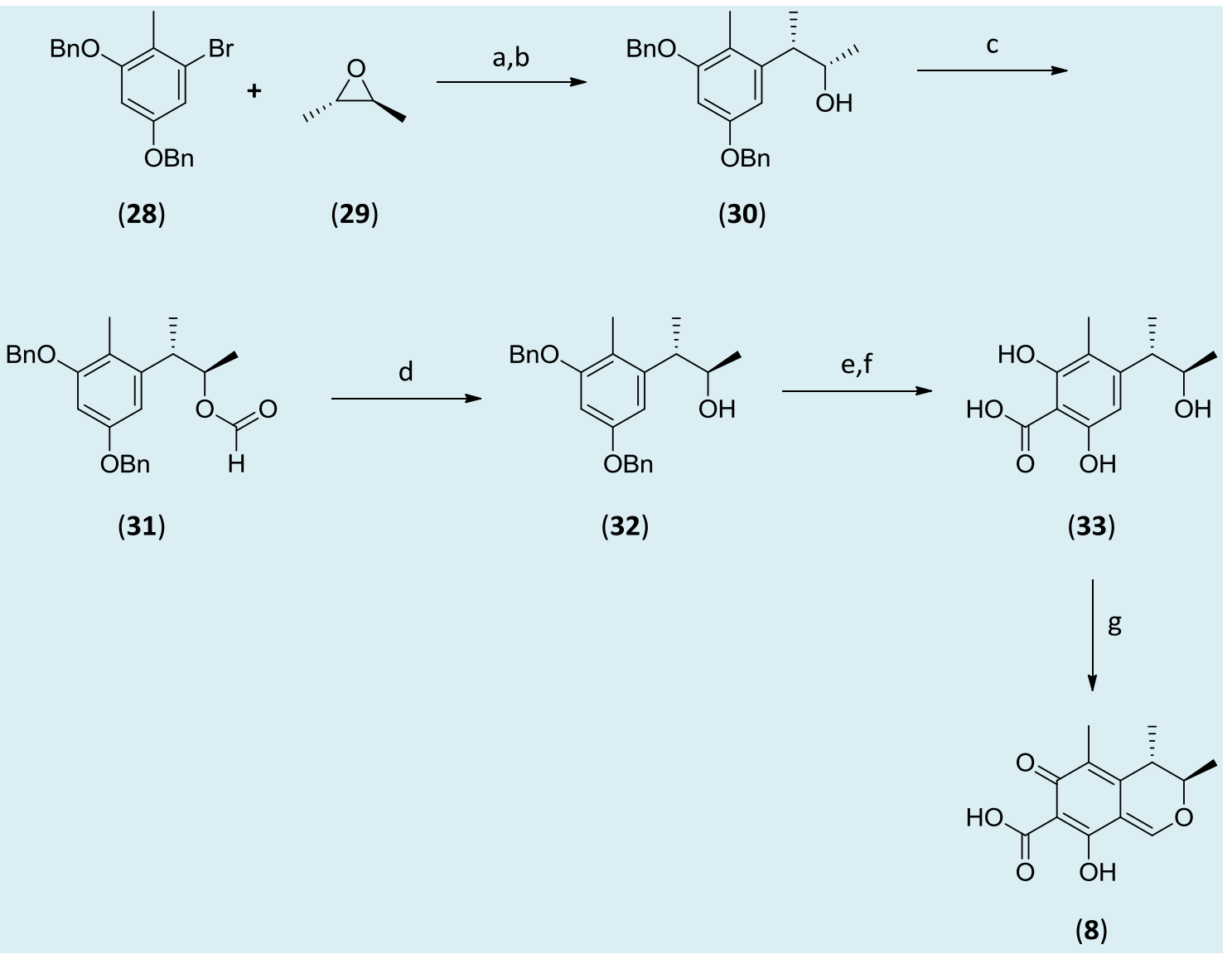

Figura 8. Esquema da Síntese da Citrinina proposto por Rodel e Gerlach. ${ }^{37}$ Reagentes e condições reacionais: a) Mg,THF; b) epóxido (29), $\mathrm{MgBr}_{2}, \mathrm{COD} \cdot \mathrm{CuCl}$; c) $\mathrm{Ph}_{3} \mathrm{P}, \mathrm{HCO}_{2} \mathrm{H}, \mathrm{DEAD}$; d) $\mathrm{KOH}, \mathrm{MeOH} / \mathrm{H}_{2} \mathrm{O} / \mathrm{THF}$, refluxo; e) $\mathrm{H}_{2}, \mathrm{Pd} / \mathrm{C}, \mathrm{AcOH}$; f) $\mathrm{KHCO}_{3}, \mathrm{CO}_{2}$, glicerol, $150{ }^{\circ} \mathrm{C}$; g) $\mathrm{HC}(\mathrm{OEt})_{3}$,

$\mathrm{HCl}$

\section{Modificações estruturais}

Poucos trabalhos relatam a formação de derivados via síntese orgânica, utilizando como material de partida a citrinina. Warren sintetizou análogos da citrinina para a formação de alquil-citrinina e alquildiidrocitrinina (Figura 9). ${ }^{38}$ Uma série homologa de derivados 1-n-alquil de citrinina que vão desde o 1-propril até 1-nonil foram preparados a partir da condensação de ortoésteres com um derivado de ácido carboxílico. Com a inserção de um grupo metil na ligação $\mathrm{C}=\mathrm{C}$ do $\mathrm{C} 1$ da citrinina, o que acarreta a perda da atividade antibiótica da molécula, voltando a aumentar com a introdução de grupos com mais de 5 carbonos. Destacando-se grupos de sete a nove carbonos nos quais a atividade antibiótica foi superior ao da citrinina. Desse modo tem-se que a atividade anti-séptica da molécula pode estar relacionada com o alongamento da cadeia substituinte no $\mathrm{C} 1$. 


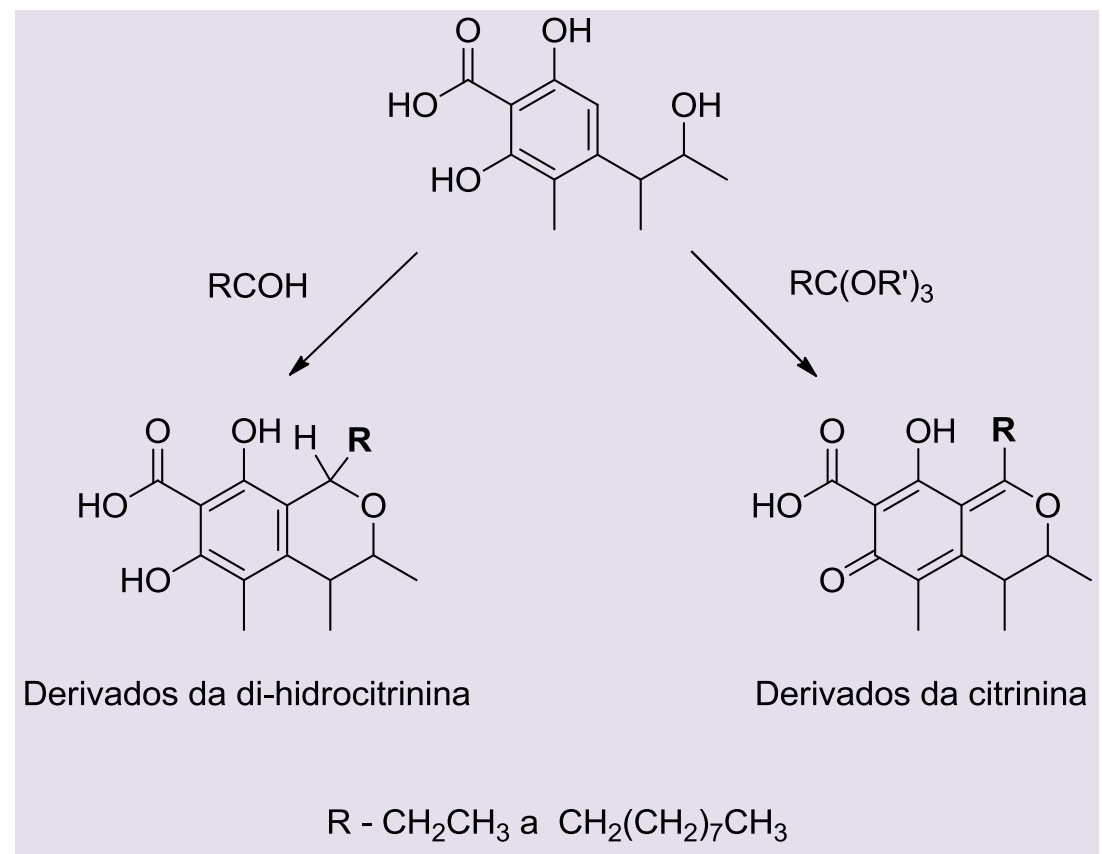

Figura 9. Síntese de derivados da citrinina proposta por Warren ${ }^{38}$

A citrinina por ser uma molécula pequena, a sua detecção através de imunoensaios é muito difícil. Alguns trabalhos sugerem que para sua melhor detecção é necessário preparar conjugados de proteína com esta toxina. ${ }^{39-41}$ Liu sintetizou utilizando a citrinina como reagente, um derivado a 8-metoxicitrinina (Figura 10) utilizando o método de metilação com a proteção da hidroxila-C8 da toxina. ${ }^{42}$ Essa proteção do grupo hidroxila, reduz a formação da ligação de hidrogênio intramolecular, expondo a grupo carboxílico da molécula. Uma vez esse grupo carboxílico exposto, ele pode ser ativado por $\mathrm{N}$ hidroxisuccinimida (NHS)

dicicloexilcarbodiimida (DCC), e em seguida a citrinina é simplesmente acoplada com a proteína, através da ligação amida.<smiles>CC1=C2C(=C(O)C(C(=O)O)C1=O)C=C[C@H](C)[C@@H]2C</smiles><smiles>COC1=C(C(=O)O)C(=O)C(C)=C2C1=CO[C@H](C)[C@H]2C</smiles>

Figura 10. Síntese do 8-MeO-Citrinina. ${ }^{42}$ a) $\mathrm{KCO}_{3},\left(\mathrm{CH}_{3}\right)_{2} \mathrm{SO}_{4}, \mathrm{~N}_{2}$, refluxo, $57^{\circ} \mathrm{C}$

\section{Atividade Biológica e Toxidez da} Citrinina

Após a descoberta da citrinina, vários estudos foram realizados a fim de observar a sua atividade biológica. A citrinina apresentou atividade antibiótica, ${ }^{43-44}$ inibidor da biossíntese de colesterol e triglicerídeos, ${ }^{48}$ inibidor da biossíntese de DNA e RNA, ${ }^{49-50}$ supressor da resposta imunitária, ${ }^{48}$ além de atividade antifúngica e antiprotozoária. ${ }^{49-50}$

A exposição de humanos a citrinina ainda não foi muito bem determinada pois, não há informações suficientes sobre o nível residual 
da toxina em alimentos. Entretanto, alguns trabalhos já vêm relatando a possibilidade de detecção da citrinina no sangue e urina humana, reavaliando a realidade da exposição humana a tal micotoxina. ${ }^{51-53}$

A citrinina é suspeita de ser o agente etiológico de nefropatologia endêmica dos Balcãs, e de tumores no trato urinário em humanos, que pode ser fatal. ${ }^{53-55} \mathrm{Em}$ doses relativamente elevadas, a citrinina é agudamente nefrotóxica em ratos, coelhos, porcos e aves, causando inflamação e necrose eventual nos rins e afetando a função do fígado em menor grau. Os valores de $\mathrm{DL}_{50}$ (dose letal) variam de acordo com a via de administração, condições fisiológicas e espécie animal. Em ratos, doses de $50 \mathrm{mg} / \mathrm{kg}$ foram relatados para a administração oral, enquanto 35 e $19 \mathrm{mg} / \mathrm{kg}$ para administração intraperitoneal em ratos e coelhos, respectivamente. ${ }^{56-57}$

A citotoxicidade da citrinina varia de forma significativa de uma cultura de célula para a outra. Citrinina aplicada em cultura de células de hepatoma em doses de até 25 $\mu \mathrm{mol} / \mathrm{L}$ foi avaliada como citostática, já em concentrações acima de $50 \mu \mathrm{mol} / \mathrm{L}$ citotóxica. ${ }^{58}$ Quando testaram o efeito de diferentes concentrações da citrinina sobre a viabilidade celular em células Vero, observaram que em doses de até $60 \mu \mathrm{mol} / \mathrm{L}$ não houve mudanças significativas. ${ }^{59}$

Os dados sobre carcinogenicidade da citrinina na literatura são escassos. Em um estudo no qual a citrinina foi incorporada na ração dos ratos no período de 80 dias, em doses de $1 \mathrm{~g} / \mathrm{Kg}$, foi observado um grande número de tumores. Entretanto, estes tumores eram benignos e considerados como adenomas celulares. Na célula, a ação da citrinina resulta no acúmulo na mitocôndria e interfere no sistema de transporte de elétrons. ${ }^{60}$ Esse processo, dependente do $\mathrm{pH}$, não afeta a integridade da membrana celular, mas provoca a inibição da síntese de DNA e, subsequentemente, de RNA e proteínas. Ainda existe muita discussão sobre a ação mutagênica da citrinina, ${ }^{61}$ inclusive estudos indicam que a citrinina não é mutagênica, porém a sua biotransformação pode transformar efeitos mutagênicos.

\section{Considerações Finais}

Atualmente uma das grandes dificuldades na medicina tem sido o tratamento de algumas doenças graves devido à resistência dos organismos aos medicamentos. Podemos citar as bactérias Staphylococcus aureus e o Enterococcus spp. envolvidas normalmente em infecções hospitalares e que se mostram resistentes aos antibióticos meticilina e vancomicina. Portanto, existe uma necessidade crescente de descoberta e de desenvolvimento de novos compostos antimicrobianos devido à resistência emergente desses organismos.

Produtos naturais fúngicos são extremamente importantes na pesquisa de novos fármacos, principalmente pela sua diversidade estrutural. Esses metabólitos fúngicos podem ser excelentes antibióticos e, ao mesmo tempo, extremamente tóxicos. Tendo assim, a possibilidade de sua utilização como medicamento descartada.

A citrinina é uma molécula capaz de produzir diversos efeitos em organismos vivos. $E$ apesar da sua toxicidade em animais, também é capaz de ser um antimicrobiano poderoso. Estudos já mostraram que a toxicidade e a bioatividade estão diretamente ligadas ao $\mathrm{C} 1$ da molécula. $\mathrm{Na}$ preparação de uma molécula biologicamente ativa, seria interessante realizar estudos envolvendo a modificação estrutural da citrinina, a fim de reduzir significativamente sua citotoxicidade sem que haja perdas na sua atividade biológica, formando novos derivados com maiores chances de sucesso.

\section{Referências Bibliográficas}

${ }^{1}$ Gunatilaka, A. Natural products from plantassociated microorganisms: distribution, structural diversity, bioactivity, and 
implications of their occurrence. Journal of Natural Products 2006, 69, 509. [CrossRef] [PubMed]

${ }^{2}$ Bennett, J. W.; Klich, M. Mycotoxins. Clinical Microbiology 2003, 16, 497. [CrossRef] [PubMed]

${ }^{3}$ Betina, V. Citrinin and Related Substances. Em: Betina, V., Mycotoxins, Production, Isolation, Separation and Purification, Elselvier, New York, 1984

${ }^{4}$ Sítio da Food Ingredients Brasil, Disponível em: <http://www.revista-

fi.com/materias/90.pdf >. Acesso em: 14 de janeiro de 2015 .

${ }^{5}$ Hetherington, A. C.; Raistrick, H. Studies in biochemistry of microoganism $\mathrm{XI}$. On the production and chemical constitution of a new yellow colouring matter, citrinin, produced from glucose by Penicillium citrinum Thom. Philosophical Transactions of The Royal Society of London Series B Biological Sciences 1931, 220, 269. [CrossRef]

${ }^{6}$ Damodaran, C.; Ramados, C. S.; Shanmugasundaram, R. B. A rapid procedure for the isolation, identification and estimation of citrinin. Analytical Biochemistry 1973, 52, 482. [CrossRef] [PubMed]

${ }^{7}$ Wong, H. C. ; Koehler, P. E. Production and isolation of an antibiotic from Monascus purpureus and its relationship to pigment production. Journal of Food Science 1981, 46, 589. [CrossRef]

${ }^{8}$ Xu, B; Jia, X; Gu, L; Sung, C. Review on the qualitative and quantitative analysis of the mycotoxin citrinin. Food Control 2006, 17, 271. [CrossRef] [PubMed]

${ }^{9}$ Pollock, A. V. Production of citrinina by 5 species of Penicillium. Nature 1947, 160, 331. [CrossRef] [PubMed]

${ }^{10}$ Ciegler, A.; Vesonder, R. F.; Jackson, L. K. Production and biological activity of patulin and citrinin from Penicillium expansum. Applied and Environmental Microbiology 1977, 33, 1004. [PubMed]

${ }^{11}$ Ei-Banna, A. A; Pitt, J. I.; Leisntner, L. Production of mycotoxins by Penicillium species. Systematic and Applied Microbiology 1987, 10, 42. [CrossRef]

12 Pohland, A.; Dowell, V.; Richards, J. Microbial Toxins In Foods and Feeds, Plenum Press, New York, 1990.

${ }^{13}$ Blanc, P. J.; Loret, M. O.; Goma, G. Production of citrinin by various species of Monascus. Biotechnology Letters 1995, 17, 291. [CrossRef]

${ }^{14}$ Hajjaj, H.; Klaébé, A.; Loret, M. O.; Goma, G.; Blanc, P. J.; François, J. Biosynthetic pathway of citrinin in the filamentous fungus Monascus ruber as revealed by ${ }^{13} \mathrm{C}$ nuclear magnetic resonance. Applied and Environmental Microbiology 1999, 65, 311. [PubMed]

${ }^{15}$ Shu, P. Y.; Lin, C. H. Simple and sensitive determination of citrinin in Monascus by GCselected ion monitoring mass spectrometry. Analytical Sciences 2002, 18, 283. [CrossRef] [PubMed]

${ }^{16}$ Li, F.; Xu, G.; Li, Y.; Chen, Y. Study on the production of citrinin by Monascus strains used in food industry. Wei Sheng Yan Jiu 2003, 32, 602. [PubMed]

${ }^{17}$ Rasheva, T. V.; Nedena, T. S.; Hallet J. N.; Kujumdzieva, A. V. Characterization of a nonpigment producing Monascus purpureus mutant strain. Antonie van Leeuwenhoek International Journal of General and Molecular Microbiology 2003, 83, 333. [CrossRef]

${ }^{18}$ Carvalho, J. C.; Pandey, A.; Babitha, S. ; Soccol, C. R. Production of monascus biopigments: an overview. Agro Food Industry Hi Tech 2003, 14, 37.

${ }^{19}$ Brown, J. P.; Cartwight, N. I.; Robertson, A.; Whalley, W. B. Structure of citrinin. Nature 1948, 162, 72. [CrossRef]

${ }^{20}$ Kovac, S. Chemical structure of citrinin. Nature 1961, 190, 1104. [CrossRef]

${ }^{21}$ Mathielson, D. W.; Whalley, W. B. The chemistry of fungi. Part XLIV.The conformation of citrinin. Journal of The Chemical Society 1964, 4640.

${ }^{22}$ Davis, N. D.; Dalby, D. K.; Diener, U. L.; Sansing, G. A. Medium-Scale Production of 
Citrinin by Penicillium citrinum in a Semisynthetic Medium. Applied Microbiology 1975, 29, 118. [PubMed]

${ }^{23}$ Wyatt, R. Production of Citrinin By Penicillium Citrinum In Different Liquid Media. Poultry Science 1977, 56, 1342. [CrossRef] [PubMed]

${ }^{24}$ Gohrt, A.; Zeeck, A.; Hutter, K.; Kirsch, R.; Kluge, $\mathrm{H}$; Thiericke, $\mathrm{R}$. Secondary metabolites by chemical screening: decarestrictines, a new family of inhibitors of cholesterol biosynthesis from Penicillium. Structrure elucidation of decarestricines A to D. Journal of Antibiotics 1992, 45, 66. [CrossRef] [PubMed]

${ }^{25}$ Malmstrøm, J.; Christophersen, C.; Frisvad, J. C. Secondary metabolites characteristic of Penicillium citrinum, Penicillium steckii and related species. Phytochemistry 2000, 54, 301. [CrossRef] [PubMed]

${ }^{26}$ Santos, C. M. C.; Costa, G. L.; FigueroaVillar, J. D. Identification of citrinin as the defense metabolite of Penicillium corylophilum stressed with the antagonist fungus Beauveria bassiana. Natural Products Research 2012, 26, 2316. [CrossRef] [PubMed]

${ }^{27}$ Le Bars, J.; Le Bars, P. Strategy for safe use of fungi and fungal derivatives in food processing. Revue de Medicine Veterinaire 1998, 149, 493. [Link]

${ }^{28}$ Birch. A. J.; Fitton, P.; Pride, E.; Ryan, A. J.; Smith, H.; Whalley, W.B. Studies in relation to biosynthesis. Part XVII. Sclerotiorin, citrinin and citromycetin. Journal of The Chemical Society 1958, 4576. [CrossRef]

${ }^{29}$ Schwenk, E.; Alexander, G. J.; Allen M. Gold, A. M.; Stevens, D. F. Biogenesis of citrinin. The Journal of Biological Chemistry 1958, 233, 1211. [PubMed]

${ }^{30}$ Rodig, O. R.; Ellis, L. C.; Glover. I. T. The biosynthesis of citrinin from Penicillium citrinum, II: Tracer studies on the formation of citrinin. Biochemistry 1966, 5, 2458. [CrossRef] [PubMed]

${ }^{31}$ Colombo, C.; Gennari, C.; Potenza, D.; Scolastico, C.; Aragozzini, F. Biosynthesis of citrinin and synthesis of its biogenetic precursors. Journal of the Chemical Society, Perkin Transactions 1 1981, 2594. [CrossRef]

${ }^{32}$ Barber, J.; Staunton, J. New insights into poliketide metabolism: the use of protium as a tracer in the biosyntesis of citrinin by Penicillium citrinum. Journal of The Chemical Society, Perkin Transactions 1 1980, 2244. [CrossRef]

${ }^{33}$ Barber, J.; Carter, R. H.; Staunton, J. The biosynthesis of citrinin by Penicillium citrinum. Journal of the Chemical Society Perkin Transactions 1 1981, 2577. [CrossRef]

${ }^{34}$ Cartwright, N. J.; Robertson, A.; Whalley, W. B. The chemistry of fungi. Part VII. Synthesis of citrinin and dihydrocitrinin. Journal of The Chemical Society 1949, 1563. [CrossRef]

${ }^{35}$ Barber, J. A.; Staunton, J.; Wilkinson, M. R. A diastereoselective synthesis of the polyketide antibiotic citrinin using toluate anion chemistry. Journal of The Chemistry Society Perkin Transactions 1 1986, 2101. [CrossRef]

${ }^{36}$ Regan, A. C.; Staunton, J. Asymmetric synthesis of (+)-citrinin using an ortho-toluate carbanion generated by a chiral base. Journal of The Chemistry Society - Chemical Communications 1987, 7, 520. [CrossRef]

${ }^{37}$ Rodel, T.; Gerlach, H. Enantioselective synthesis of the polyketide antibiotic $(3 R, 4 S)$ (-)-citrinin. Liebigs Annalen 1995, 5, 885. [CrossRef]

${ }^{38}$ Warren, H. H.; Finkelstein, M., Scola, A. The synthesis and antibacterial activity of analogs of citrinin and dihydrocitrinin. Journal of The American Chemistry Society 1962, 84, 1926. [CrossRef]

${ }^{39}$ Abramson, D.; Usleber, E.; Martlbauer, E. An indirect enzyme immunoassay for the mycotoxin citrinin. Applied and Environmental Microbiology 1995, 61, 2007. [Link]

${ }^{40}$ Kononenko, G.; Burkin, A. Immunoenzyme method for the determination of citrinin. Journal of Analytical Chemistry 2007, 62, 691. [CrossRef]

${ }^{41}$ Duan, Z. H.; Lin, Z. S.; Yao, H. R.; Gao, Y. H.; Zhang, K.; Zhao, S. Q.; Zhu, Z. Y. Preparation of artificial antigen and egg yolk-derived immunoglobulin (IgY) of citrinin for enzymelinked immunosorbent assay. Biomedical and 
Environmental Sciences 2009, 22,237. [CrossRef] [PubMed]

${ }^{42}$ Liu, A.; Zhou, Y.; Zhang, Y.; Chen, F.; Wang,

$X$. Preparation of cit-protein conjugates using a novel citrinin derivative as hapten. European Food Research and Technology $A$ 2011, 232, 289. [CrossRef]

${ }^{43}$ Wang, Y.; Hong, F. K.; Hwang, F. T.; Fan, C. S. Citrinin as an antibiotic. Science 1947, 26 , 291. [CrossRef]

${ }^{44}$ Warren, H. H.; Dougherty, G.; Wallis, E. The synthesis and antibiotic activity of analogs of citrinina and dihydrocitrinin. Journal of American Chemistry Society 1957, 79, 3812. [CrossRef]

${ }^{45}$ Endo, A.; Kuroda, M. Citrinin, an inhibitor of cholesterol synthesis. The Journal of Antibiotics 1976, 29, 841. [CrossRef] [PubMed]

${ }^{46}$ Liu, B. H.; Yu, F. Y.; Wu, T. S.; Li, S. Y.; Su, M. C.; Wang, M. C.; Shih, S. M. Evaluation of genotoxic risk and oxidative DNA damage in mammalian cells exposed to mycotoxins, patulin and citrinin. Toxicology and Applied Pharmacology 2003, 191, 255. [CrossRef] [PubMed]

${ }^{47}$ Wasternack, C.; Weisser, J. Inhibition of RNA-synthesis and DNA-synthesis by citrinin and its effects on DNA precursor-metabolism in v79-e-cells. Comparative Biochemistry and Physiology Part B: Comparative Biochemistry 1992, 101, 225. [CrossRef] [PubMed]

${ }^{48}$ Carvalho, C. A.; Fernandes, B. C. T. M., Freire, R. B. Supressão da resposta imunitária humoral causada pela citrinina. Arquivo Brasileiro de Medicina Veterinária e Zootecnia 2005, 57, 171. [CrossRef]

${ }^{49}$ Betina, V.; Baráthová, H. Citrinin - an inducer of permeability changes in Eremothecium ashbyi. The Journal of Antibiotics 1968, 21, 1968. [CrossRef] [PubMed]

${ }^{50}$ Franco, C. M.; Fente, C. A.; Vasquez, B.; Cepeda, A.; Lallaoui, L.; Prognon, P.; Mahuzier, G. Simple and sensitive highperformance liquid chromatography fluorescence method for the determination of citrinin - Application to the analysis of fungal cultures and cheese extracts. Journal of Chromatography A 1996, 723, 69. [CrossRef] [PubMed]

${ }^{51}$ European Food Safety Authority. Scientific opinion on the risks for public and animal health related to the presence of citrinin in food and feed. EFSA Journal 2012, 10, 2605. [CrossRef]

${ }^{52}$ Blaszkewicz, M.; Muñoz, K.; Degen, G.H. Methods for analysis of citrinina in human blood and urine. Archives of Toxicology 2013, 87, 1087. [CrossRef] [PubMed]

${ }^{53}$ Flajs, D.; Peraica, M. Toxicological properties of citrinin. Archives of Industrial Hygiene and Toxicology 2009, 60, 457. [CrossRef] [PubMed]

${ }^{54}$ Peraica, M.; Domijan, A. M.; MileticMedved, M.; Fuchs, R. The involvement of mycotoxins in the development of endemic nephropathy. Wiener Klinische Wochenschrift 2008, 120, 402. [CrossRef] [PubMed]

${ }^{55}$ Vrabcheva, T.; Usleber, E.; Dietrich, R., Martlbauer, E. Co-occurrence of ochratoxin A and citrinin in cereals from Bulgarian villages with a history of Balkan endemic nephropathy. Journal of Agricultural and Food Chemistry 2000, 48, 2483. [CrossRef] [PubMed]

${ }^{56}$ Friis, P.; Hasselager, E.; Krogh, P. Isolation of citrinin and oxalic acid from Penicillium viridicatum Westling and their nephrotoxicity in rats and pigs. Acta Pathologica Microbiologica Scandinavica 1969, 77, 559. [CrossRef] [PubMed]

${ }^{57}$ Ambrose, A. M.; De, F. eds.; Some toxicological and pharmacological properties of citrinin. Journal of Pharmacology and Experimental Therapeutics 1946, 88, 173. [PubMed]

${ }^{58}$ Lorkowski, G.; Creppy, E. E.; Beck, G.; Dirheimer, G.; Roschenthaler, R. Inhibitory action of citrinin on cultured hepatoma cells. Food and Cosmetics Toxicology 1980, 18, 489. [CrossRef] [PubMed]

${ }^{59}$ Bouslimi, A.; Bouaziz, C.; Ayed-Boussema, I.; Hassen, W.; Bacha, H. Individual and combined effects of ochratoxin $A$ and citrinin 
on viability and DNA fragmentation in cultured Vero cells and on chromosome aberrations in mice bone marrow cells. Toxicology 2008, 251, 1. [CrossRef] [PubMed] ${ }^{60}$ Ribeiro, S. M.; Chagas, G. M.; Campelo, A. P.; Kluppel, M. L. Mechanism of citrinininduced dysfunction of mitochondria. V. Effects on the homeostasis of reactive oxygen species. Cell Biochemistry and Function 1997, 15, 203. [CrossRef] [PubMed]

${ }^{61}$ Sabater-Vilar, M.; Roel, F. M. M.; FinkGremmels, J. Mutagenicity of commercial Monascus fermentation products and the role of citrinina contamination. Mutation Research 1999, 444, 7. [CrossRef] [PubMed] 